\title{
Budaya Organisasi SEJUK.ORG dalam Memproduksi Berita Bernilai Keberagaman
}

\author{
Nathania, Eko Harry Susanto \\ nathaniawahyudil@gmail.com,ekos@fikom.untar.ac.id
}

Fakultas Ilmu Komunikasi Universitas Tarumanagara

\begin{abstract}
This research was motivated by SEJUK which is one of the news portal of private online media that are networked in Indonesia. SEJUK stand for Serikat Jurnalis untuk Keberagaman. SEJUK highly upholds news content that contains the value of diversity, the diversity news includes religious values, gender, human rights and multiculturalism. As an online media container that accommodates and discusses an issue of diversity, SEJUK adheres to not preaching news that can discriminate because it can damage the diversity. A company must be able to implement an organizational culture for its workers, as well as SEJUK.ORG. Organizational culture is needed for workers as a guideline and also guidance in producing news that is of diversity. In this study, the authors analyzed organizational culture at SEJUK.ORG used two assumptions from Organizational Culture Theory proposed by Michael Pacanowsky \& Nick O'Donnel Trujillo. The approach used is qualitative, with ethnographic methods because the authors observe directly within approximately two months.
\end{abstract}

Keywords: Organizational Culture, Diversity, Verbal and Nonverbal Communication

\begin{abstract}
Abstrak
Penelitian ini dilatarbelakangi oleh SEJUK yang merupakan salah satu portal berita media online swasta berjaringan di Indonesia. SEJUK merupakan singkatan dari Serikat Jurnalis untuk Keberagaman. SEJUK menjunjung tinggi konten berita yang bernilai keberagaman. Berita keberagaman tersebut meliputi nilai agama, gender, HAM dan multikulturalisme. Sebagai suatu wadah media online yang menampung dan membahas suatu isu keberagaman, SEJUK berpegang teguh dengan tidak memberitakan berita yang dapat mendiskriminasi karena hal tersebut dapat merusak keberagaman. Sebuah perusahaan harus mampu menerapkan suatu budaya organisasi bagi para pekerjanya, begitu pula dengan SEJUK.ORG. Budaya organisasi diperlukan bagi pekerja sebagai pedoman dan juga panduan dalam menghasilkan berita yang bernilai keberagaman. Dalam penelitian ini, penulis menganalisis budaya organisasi di SEJUK.ORG menggunakan dua asumsi dari teori budaya organisasi yang dikemukakan oleh Michael Pacanowsky \& Nick O’Donnel Trujillo. Pendekatan yang digunakan adalah kualitatif, dengan metode etnografi karena penulis mengamati secara langsung dalam kurun waktu yang kurang lebih adalah dua bulan.
\end{abstract}

Kata Kunci: Budaya Organisasi, Keberagaman, Komunikasi Verbal dan Nonverbal

\section{Pendahuluan}

Sebuah perusahaan harus mampu melaksanakan suatu budaya organisasi bagi pekerjanya, termasuk dengan SEJUK.ORG. Budaya organisasi ini berfungsi sebagai pedoman untuk para pekerjanya dalam memproduksi sebuah program berita yang berkualitas. Dengan terciptanya budaya organisasi yang kuat dalam sebuah perusahaan, tujuan perusahaan pun dapat terwujud dengan baik. Penelitian ini 
mencoba melihat dan mengamati bagaimana budaya organisasi yang ada di SEJUK.ORG, sehingga mampu memproduksi berita-berita bernilai keberagaman.

Fokus penelitian ini adalah pada budaya organisasi yang mencakup nilai-nilai organisasi dan juga simbol-simbol yang sudah diterapkan oleh organisasi. Nilai-nilai organisasi tersebut meliputi ideologi dan peraturan-peraturan organisasi, sedangkan simbol-simbol meliputi komunikasi verbal dan nonverbal. Penulis menggunakan dua asumsi dari Richard West dan Lynn H. Turner (2007) mengenai Teori Budaya Organisasi (Organizational Cultute Theory) yaitu: 1. Suatu anggota organisasi harus mampu untuk membuat dan mewujudkan keinginan organisasi secara bersama, hal ini dapat berakibat pada perkembangan tentang nilai-nilai dalam organisasi tersebut. 2. Dalam suatu budaya organisasi sangat penting untuk menggunakan dan menginterpretasikan simbol-simbol agar organisasi berjalan dengan baik dan lancar.

Berdasarkan hal tersebut penulis melakukan identifikasi masalah dengan mencari apa saja nilai-nilai organisasi yang dianut SEJUK dalam memproduksi konten berita yang bernilai keberagaman; konsistensi penggunaan dan interpretasi simbol verbal dan nonverbal jurnalis SEJUK dalam memproduksi konten berita yang bernilai keberagaman. Dengan demikian, rumusan masalah penelitian ini yakni bagaimana budaya organisasi SEJUK dalam memproduksi suatu berita yang bernilai keberagaman.

Tujuan dari penelitian ini adalah untuk mengetahui apa saja nilai-nilai organisasi yang dianut oleh SEJUK dalam memproduksi konten berita yang bernilai keberagaman; untuk mengetahui bagaimana penggunaan dan interpretasi simbol verbal dan nonverbal jurnalis SEJUK dalam memproduksi konten berita yang bernilai keberagaman.

\section{Metode Penelitian}

Penulis menggunakan pendekatan penelitian kualitatif dengan metode etnografi komunikasi. Metode kualitatif menurut Bogdan dan Taylor (dalam Moleong, 2011) metodologi kualitatif ini diartikan sebagai suatu penelitian yang hasilnya adalah penjabaran yang bersifat deskriptif yang meliputi tulisan maupun lisan dari subjek atau objek yang diamati. Pendekatan kualitatif akan lebih banyak meneliti kehidupan yang tidak jauh dari lingkungan sekitar seperti kegiatan sehari-hari, menganalisis, mencari makna dari suatu konteks tertentu. Pendekatan kualitatif ini juga dapat dipergunakan untuk penelitian kehidupan masyarakat, sejarah, tingkah laku, fungsi organisasi, peristiwa tertentu, pergerakan-pergerakan sosial, dan hubungan kekerabatan dalam kekeluargaan. Penelitian ini menggunakan pendekatan kualitatif karena penelitian ini dilakukan untuk melihat bagaimana budaya organisasi yang sudah dilaksanakan oleh para jurnalis SEJUK.ORG.

Penelitian ini menggunakan metode penelitian etnografi, metode etnografi merupakan salah satu cara untuk menpelajari suatu objek secara mendalam, sistematik dan sesuai sebagaimana hakikat objek tersebut (Moleong, 1990). Dalam penelitian ini, penulis menjadikan para jurnalis SEJUK.ORG sebagai subjek penelitian, sedangkan objek penelitian adalah budaya organisasi yang terdapat di SEJUK.ORG.

Dalam penelitian ini, penulis melakukan observasi dan wawancara yang mendalam untuk dapat mengumpulkan data, penulis juga mengumpulkan data melalui data primer dan juga sekunder. Untuk mendapatkan data yang akurat penulis melakukan wawancara dengan tujuh informan yang berkaitan dengan SEJUK.ORG. 
Teknik analisis data yang penulis gunakan adalah teknik analisis menurut Miles dan Huberman (dalam Susanto, 2018) model analisis data penelitian kualitatif dilakukan melalui proses sebagai berikut: (1) reduksi data sebagai proses pemilihan, pemusatan perhatian pada penyedarhanaan, pengabstrakan dan transformasi data kasar yang muncul dari catatan-catatan di lapangan; (2) penyajian data sebagai sekumpulan informasi tersusun yang member kemungkinan adanya penarikan kesimpulan dan pengambilan tindakan. Penciptaan dan penggunaan penyajian data tidaklah terpisah dari analisis; (3) menarik kesimpulan atau verifikasi merupakan kegiatan analisis yang ketiga, dari permulaan pengumpulan data seorang penganlisis kualitatif mulai mencari arti benda-benda, mencatat keteraturan, pola-pola, penjelasan, konfigurasi alur sebab akibat dan proposisi.

\section{Hasil Temuan dan Diskusi}

Nilai-nilai Keberagaman yang dianut oleh SEJUK.ORG

Dalam Teori Budaya Organisasi (Organizational Culture Theory) yang dikemukakan oleh Michael Pacanowsky dan Nick O'Donnel Trujillo terdapat asumsi yang menyebutkan anggota-anggota organisasi menciptakan dan mempertahankan perasaan yang dimiliki bersama mengenai realitas organisasi, yang berakibat pada pemahaman yang lebih baik mengenai nilai-nilai sebuah organisasi. Nilai disini merujuk kepada pengertian suatu standar dan juga prinsip yang dimiliki oleh budaya organisasi. Dalam hal ini, penulis mengartikan standar dan prinsip tersebut menjadi ideologi dan peraturan-peraturan organisasi yang dimiliki oleh SEJUK.ORG. Ideologi dan peraturan merupakan suatu hal yang penting yang menjadi dasar berlangsungnya sebuah organisasi. Oleh karena itu, penulis menjelaskan tentang ideologi dan peraturan-peraturan yang ada pada SEJUK.ORG di dalam membuat konten berita yang bernilai keberagaman. Sebagai organisasi, SEJUK.ORG juga memiliki ideologi dan juga peraturan yang menjadi nilai dasar mereka untuk bertahan selama ini dan juga menghasilkan konten-konten berita.

Berdasarkan dari asumsi pertama yang dikemukakan oleh Pacanowsky dan O'Donnel Trujillo dalam Teori Budaya Organisasi (Organizational Culture Theory), perilaku anggota organisasi akan dipengaruhi oleh peraturan-peraturan yang diciptakan serta diterapkan bagi para jurnalis di SEJUK.ORG, sehingga mereka akan mampu menghasilkan sebuah konten-konten atau berita-berita yang bernilai keberagaman.

Tabel 1. Nilai-nilai Keberagaman

\begin{tabular}{lll}
\hline No. & Nilai-nilai Organisasi & \multicolumn{1}{c}{ Keterangan } \\
\hline 1. & Ideologi & Keberagaman atau pluralism \\
2. & Peraturan-peraturan & $\begin{array}{l}\text { Pedoman atau panduan untuk para jurnalis } \\
\text { dalam membuat suatu berita (keberagaman } \\
\end{array}$ \\
& & $\begin{array}{l}\text { \& tidak menulis berita yang } \\
\text { mendiskriminasi pihak tertentu) }\end{array}$ \\
\hline
\end{tabular}

Sumber: Dokumentasi Peneliti (2018)

Menurut Robbins (dalam Sembiring, 2012) budaya organisasi mengacu kepada suatu sistem makna bersama yang dianut oleh para anggota organisasi dan membedakan antara suatu organisasi dengan organisasi lainnya. Budaya organisasi 
yang selama ini sudah diterapkan oleh SEJUK.ORG memiliki pengaruh yang sangat berdampak pada kemajuan organisasi tersebut, mulai dari cara menulis berita sampai mencari berita yang memiliki nilai keberagaman. Dengan budaya organisasi yang sudah ada dan diterapkan dengan cara yang baik dan benar, SEJUK.ORG sudah semakin berkembang dan maju sebagai media online yang membela isu keberagaman.

Sampai saat ini SEJUK.ORG dalam pemberitaannya berorientasi kepada keberagaman. SEJUK.ORG juga mengkategorikan jenis-jenis keberagaman itu dalam konten-konten beritanya, seperti yang terlihat di website SEJUK.ORG terdapat kolom untuk memilih berita-berita yang sesuai dengan yang ingin kita cari atau ingin kita baca. Konten-konten tersebut dibagi menjadi empat bagian, yaitu: agama, gender, HAM, multikulturalisme. Kolom agama yang terdapat pada web SEJUK.ORG yaitu berisi mengenai konten-konten berita yang bersangkutan oleh keagamaan atau kepercayaan-kepercayaan yang ada di Indonesia. Contohnya adalah seperti berita pembubaran gereja, dan lain-lain. Kolom gender membahas topik mengenai kesetaraan gender, kekerasan pada perempuan. Contohnya adalah seperti berita kolom HAM lebih mengangkat topik mengenai LGBT, disabilitas. Sedangkan kolom multikulturalisme membahas topik mengenai perbedaan budaya yang ada di negara Indonesia.

\section{Penggunaan dan Interpretasi Simbol Verbal dan Nonverbal Jurnalis SEJUK.ORG}

Sesuai dengan asumsi kedua pada Teori Budaya Organisasi (Organizational Culture Theory) yang telah dikemukakan oleh Pacanowsky \& O'Donnel Trujillo, di dalam suatu organisasi pasti terdapat simbol-simbol, simbol-simbol tersebut juga memiliki arti. Anggota-anggota organisasi pasti menciptakan, menggunakan serta menginterpretasikan simbol setiap harinya. Simbol-simbol yang dimaksud tersebut meliputi komunikasi verbal dan nonverbal yang ada di dalam suatu organisasi. Dalam hal ini, penulis memfokuskan komunikasi verbal dan nonverbal yang tercipta di antara sesama jurnalis di SEJUK.ORG sehingga mampu menghasilkan konten berita yang bernilai keberagaman.

Komunikasi verbal adalah kegiatan penciptaan dan pertukaran pesan yang menggunakan simbol-simbol atau kata-kata dengan cara lisan maupun tulisan. Komunikasi verbal menjadi salah satu komunikasi yang paling banyak digunakan dalam hubungan antar sesama manusia. Komunikasi verbal juga menjadi salah satu komunikasi yang paling efektif untuk digunakan, karena tingkat kesalah pahaman yang terjadi cenderung sedikit. Sedangkan komunikasi nonverbal adalah komunikasi yang melibatkan gerakan tubuh, sikap tubuh maupun ekspresi wajah yang lebih sulit untuk diartikan untuk sebagaian orang, karena tidak menggunakan kata-kata secara langsung sehingga tingkat kesalah pahaman dalam komunikasi nonverbal ini lebih tinggi dibandingkan dengan komunikasi verbal.

Di SEJUK.ORG komunikasi verbal yang dilakukan pimpinan kepada bawahan berlangsung dengan terbuka, santai dan akrab. Bahkan tidak jarang penulis melihat mereka dapat bercanda satu sama lain, sehingga sulit dibedakan antara status mereka di SEJUK.ORG. Contoh komunikasi verbal antara manajer program dengan jurnalis adalah saat ingin melakukan peliputan, sebelum melakukan peliputan tersebut pasti jurnalis di briefing terlebih dahulu oleh manajer program, selain itu mereka juga bisa bertukar pikiran, bagaimana membuat beritanya sudah ditentukan terlebih dahulu, sehingga hal tersebut sangat membantu jurnalis saat melakukan peliputan. Sedangkan untuk komunikasi nonverbal, mereka saling memberikan semangat 
Nathania, Eko Harry Susanto: Budaya Organisasi SEJUK.ORG Dalam Memproduksi Berita Bernilai Keberagaman

kepada jurnalis lainnya, khususnya bagi jurnalis senior yang membimbing jurnalis magang yang sering memberikan semangat dengan menepuk pundak sebagai tanda dukungan dari mereka.

Tabel 2. Komunikasi Verbal dan Nonverbal

\begin{tabular}{|c|c|c|}
\hline No. & Komunikasi & Keterangan \\
\hline 1. & Verbal & $\begin{array}{l}\text { Terjadi langsung saat melakukan } \\
\text { diskusi atau pertemuan bulanan } \\
\text { antara sesama jurnalis dan } \\
\text { pekerja di SEJUK.ORG }\end{array}$ \\
\hline 2. & Nonverbal & $\begin{array}{l}\text { Terjadi saat jurnalis saling } \\
\text { memberikan semangat, dengan } \\
\text { cara menepuk pundak jurnalis } \\
\text { lainnya }\end{array}$ \\
\hline
\end{tabular}

Sumber: Dokumentasi Peneliti (2018)

Robbins (1996) mendefinisikan suatu budaya organisasi mengacu kepada suatu sistem makna bersama yang dianut oleh para anggotanya dan yang membedakan antara suatu organisasi dengan organisasi lainnya. Robbins juga mengatakan ada tujuh ciri-ciri dari budaya organisasi, yakni:

1) Inovasi dan pengambilan resiko. Dimana karyawan diajarkan untuk menjadi inovatif sehingga menjadi kreatif dan tidak monoton, dan juga berani dalam mengambil sebuah resiko.

2) Perhatian terhadap detail. Karyawan dilatih untuk dapat menganalisis dengan baik serta menunjukkan kecerdasan dan juga dibutuhkan ketelitian.

3) Orientasi hasil. Manajemen lebih fokus kepada hasil bukan kepada teknik dan proses yang digunakan untuk mencapai hasil tersebut.

4) Orientasi orang. Bagaimana keputusan manajemen memperhitungkan efek pada orang-orang di dalam organisasi itu.

5) Orientasi tim. Kegiatan kerja yang diorganisasikan melalui pembentukan sebuah tim, bukan melalui individu atau personal.

6) Keagresifan. Berkaitan dengan keaktifan karyawan dalam berorganisasi.

7) Kemantapan. Organisasi sangat ingin untuk mempertahankan budaya organisasi yang dianut dengan baik.

Berdasarkan tujuh ciri-ciri budaya organisasi tersebut, penulis mengamati bahwa SEJUK.ORG memiliki beberapa ciri-ciri tersebut. Ciri-ciri tersebut diantarnya adalah jurnalis di SEJUK.ORG secara tidak langsung melakukan inovasi terhadap media yang sudah banyak di Indonesia, SEJUK.ORG mengambil tema keberagaman agar tidak menjadi sama seperti media lain, SEJUK.ORG sekaligus juga mengambil resiko karena adanya keputusan pengambilan tema tersebut sebagai dasar berdirinya SEJUK.ORG, dengan mengambil tema atau budaya itu SEJUK.ORG banyak mendapatkan ancaman dari pihak-pihak yang tidak suka dengan pemberitaan tersebut.

Jurnalis SEJUK.ORG juga harus memperhatikan secara detail bagaimana seharusnya berita tersebut dapat dikemas dengan baik, agar menjadi menarik untuk dibaca dan juga tidak memihak kepada satu pihak, SEJUK.ORG harus melakukan cover both side karena budaya dari SEJUK.ORG adalah keberagaman maka SEJUK.ORG tidak akan memberitakan berita yang mendiskriminasi. SEJUK.ORG 
sangat berorientasi kepada sebuah hasil, berita-berita yang sudah SEJUK.ORG buat sangat penting bagi seluruh pembaca SEJUK.ORG. Maka dari itu SEJUK.ORG tidak peduli terhadap proses atau teknik untuk mendapatkan hasil tersebut, tetapi SEJUK.ORG lebih fokus kepada bagaimana hasil tersebut nantinya. Jurnalis SEJUK.ORG boleh melakukan apa saja, tidak terdapat aturan-aturan yang ketat untuk para jurnalis SEJUK.ORG mereka semua mendapatkan kebebasan dalam cara mereka sendiri, yang terpenting adalah hasil yang mereka kerjakan harus sesuai dengan standar SEJUK.ORG.

Menjadi jurnalis diperlukan sebuah agresivitas. Jika tidak agresif, jurnalis tidak akan mendapatkan berita. Agresif yang dimaksud yakni para jurnalis harus mencari tanggapan atas informasi-informasi liputan yang telah dikumpulkan. Misalnya, terdapat informasi liputan untuk lusa, maka jurnalis tidak boleh hanya diam saja, melainkan harus agresif menanyakan dimana lokasi liputan, bagaimana ide yang harus dibuat untuk melakukan peliputan tersebut, agresif dalam memikirkan angle pemberitaan yang akan diliput. Jika tidak mengerti bahan liputan, jurnalis harus bertanya kepada jurnalis lainnya untuk membantu memahami. SEJUK.ORG yakin dengan budaya organisasi yang telah mereka bangun selama ini. Bagi para pekerja di SEJUK.ORG, budaya organisasi tersebut sudah berjalan dengan baik.

\section{Simpulan}

Jurnalis SEJUK.ORG menerapkan nilai-nilai organisasi untuk menghasilkan konten-konten berita yang bernilai keberagaman. Nilai-nilai tersebut meliputi ideologi dan peraturan yang dimiliki oleh para jurnalis di SEJUK.ORG. Nilai-nilai yang harus dimiliki oleh para jurnalis di SEJUK.ORG dalam menghasilkan konten berita bernilai keberagaman adalah suatu nilai pluralisme atau keberagaman itu sendiri, sesuai dengan slogan SEJUK.ORG akan merawat keberagaman dan membela yang terpinggirkan. Selain itu, jurnalis di SEJUK.ORG juga memegang teguh prinsip untuk tidak memberitakan berita yang dapat mendiskriminasi suatu pihak, karena hal tersebut merusak keberagaman.

Jurnalis SEJUK.ORG menerapkan komunikasi verbal dan nonverbal yang efektif dalam membuat suatu konten berita yang bernilai keberagaman. Dalam SEJUK.ORG komunikasi dapat dilakukan melalui atasan kepada bawahan, bawahan kepada atasan, maupun sesama jabatan. Maka dari itu komunikasi yang terdapat di SEJUK.ORG dapat dikatakan lancar, karena semua dapat berkomunikasi dengan baik. Komunikasi tersebut dapat terlihat dari diskusi-diskusi yang selalu dilakukan oleh para jurnalis SEJUK.ORG di dalam kantor secara verbal, dan juga dukungan melalui bahasa tubuh dari para jurnalis SEJUK.ORG sebagai komunikasi nonverbal.

\section{Ucapan Terima Kasih}

Penulis mengucapkan terima kasih yang dalam untuk para jurnalis SEJUK.ORG yang sudah bersedia meluangkan waktunya dan juga sudah memberikan informasi kepada penulis untuk melengkapi data-data dalam penelitian ini, sehingga penelitian ini dapat terselesaikan dengan baik. Terima kasih juga untuk pembimbing yang sudah meluangkan waktu, tenaga serta pikiran dalam memberikan arahan dan masukkan yang sangat bermanfaat dalam penelitian ini. Terima kasih juga untuk kedua orang tua dan juga teman-teman penulis yang tidak henti 
Nathania, Eko Harry Susanto: Budaya Organisasi SEJUK.ORG Dalam Memproduksi Berita Bernilai Keberagaman

memberikan doa dan juga semangat untuk penulis menyelesaikan penelitian ini, sehingga penelitian ini dapat dipublikasikan.

\section{Daftar Pustaka}

Anggarin, Rosita. (2014). Berita Terjemahan Pada Situs Media Online (Tinjauan Proses Penerjemahan Pada Rubrik Internasional \& Rubrik Celebrity-World Celeb dalam Okezone.com). Jurnal Komunikasi Universitas Tarumanagara Jakarta. Vol.6 No.3.

Moleong, L.J. (2011). Metodelogi Penelitian Kualitatif Edisi Revisi. Bandung: PT Remaja Rosdakarya.

Muhammad, Arni. (2005). Komunikasi Organisasi. Jakarta: Bumi Aksara.

Robbins, Stephen P. (1996). Perilaku Organisasi, Konsep, Kontroversi dan Aplikasi (Edisi Keenam). Jakarta: PT Bhuana Ilmu Popular.

Sembiring, Masana. (2012). Budaya dan Kinerja Organisasi. Bandung: Fokusmedia.

Susanto, Harry Eko. (2018). Komunikasi Manusia: Teori dan Praktek Dalam Penyampaian Gagasan. Jakarta: Mitra Wacana Media.

West, R., \& Lynn H. Turner. (2007). Pengantar Teori Komunikasi. Jakarta: Salemba Humanika.

Winardi. (2009). Teori Organisasi \& Pengorganisasian. Jakarta: PT Raja Grafindo Persada. 